\title{
$\begin{array}{r}\text { WAGENINGEN } \\ \text { UNIVERSITY \& RESEARCH } \\ \hline\end{array}$
}

How and where to map supply and demand of ecosystem services for policyrelevant outcomes? Letter to the Editor

Schröter, M., Remme, R. P., \& Hein, L. G.

This is a "Post-Print" accepted manuscript, which has been published in "Ecological Indicators"

This version is distributed under a non-commercial no derivatives Creative Commons

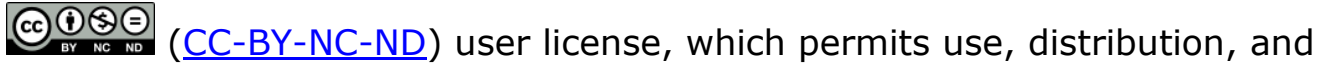
reproduction in any medium, provided the original work is properly cited and not used for commercial purposes. Further, the restriction applies that if you remix, transform, or build upon the material, you may not distribute the modified material.

Please cite this publication as follows:

Schröter, M., Remme, R. P., \& Hein, L. G. (2012). How and where to map supply and demand of ecosystem services for policy-relevant outcomes? Letter to the Editor. Ecological Indicators, 23, 220-221. https://doi.org/10.1016/j.ecolind.2012.03.025 
Letter to the Editor

\section{How and where to map supply and demand of ecosystem services for policy- relevant outcomes?}

Burkhard et al. (in press) present a new approach to map supply and demand of ecosystem services (ES) in order to support sustainability assessment and decision making. Their work contributes to the development of mapping of supply and demand of ES and we agree that this helps to inform policy makers. Mapping approaches can identify "winners" and "losers" of land use decisions. Maps are of interest especially when ecological and institutional scales do not match and when beneficiaries are situated in geographically different locations from the service provisioning area. Additionally, a spatially explicit approach can contribute to the development of policy instruments aimed at managers of ecosystems or beneficiaries of ES. Such instruments can help to reach a sustainable balance between supply and demand of certain services (i.e. socially optimal levels). Burkhard et al. (in press) make an important contribution to the development of mapping supply and demand of ES. However, to further advance this methodology several aspects need to be further explored. These are (1) the definition of the beneficiary, (2) the degree of rivalry of ES, (3) the spatial explicitness of demand, (4) the spatial explicitness of supply, and (5) the scoring system for supply and demand. We briefly discuss these aspects in this letter.

\section{Who is a beneficiary?}

ES can be typified as either intermediate or final services (Boyd and Banzhaf, 2007). Burkhard et al. (in press) state that "demand for ES is the sum of all goods and services currently consumed or used". However, clarification is needed on who is a beneficiary of an ES: is it an individual that enjoys the ES directly or is it an intermediate agent that uses ES as an input for production of a final service? The service "global climate regulation" can occur in two forms. First, a stable climate provides good living conditions for people. In this case demand is high at people's homes (see also Burkhard et al., in press, Fig. 3). Second, a stable climate is an input factor in the provision of other ES. It can be mapped as an intermediate service at vulnerable places (e.g. rice fields), as Burkhard et al. (in press) do. However, there is a risk that this service would be doublecounted when it is mapped at rice fields and as the final provisioning service "crops", as done by Burkhard et al. (in press). It appears as if Burkhard et al. (in press) also doublecount the intermediate service "pollination". Here, intermediate demand is expressed at the orchard (land cover class [LCC] "fruit trees and berries"), and final demand is expressed at the place of consumption of "crops" (LCC "continuous urban fabric").

\section{Degree of rivalry}

Burkhard et al. (in press) assign scores to supply and demand of different ES and subsequently subtract demand from supply. The result is a balance that shows under- or oversupply for different LCC. However, we think that it is necessary to consider the degree of rivalry of an ES in order to meaningfully map ES (cf. Kemkes et al., 2010). An ES is rival if the use of the service by an individual prevents others from using it. Energy can only be used once, thus creating a balance for energy can be useful. However, in the case of a non-rival ES, the use of the service by an individual does not have a significant impact on other beneficiaries of this service. People benefiting from flood protection do not have an impact on other people benefiting from it. A balance, as presented by 
Burkhard et al. (in press) in Fig. 4, can thus not meaningfully explain the relation between supply and demand for non-rival ES.

\section{Spatial explicitness of demand}

ES can show various degrees of spatial explicitness (Costanza, 2008; Fisher et al., 2009; Willemen et al., 2010). This spatial explicitness is not fully considered by Burkhard et al. (in press). In their demand matrix (Fig. 3), they allocate high scores to different ES at people's homes (LCC continuous urban fabric), for instance for "flood protection", "crops", "freshwater", "recreation and aesthetic". They explain that provisioning services are traded and distributed whereas the supply of others, mainly regulating services, is spatially fixed. They map tradable services at the place of consumption and illustrate this for energy supply and demand. Supply and demand of the ES are completely decoupled in this case, i.e. energy which is generated locally is probably not the same as energy which is consumed locally. As interregional or even international trade is characteristic of many provisioning services we think that we need an argumentation per service on where to allocate demand, when assessing it at a local or regional scale.

\section{Spatial explicitness of supply}

Some ES are spatially confined and only come into existence if certain spatial conditions are met. Pollination is a service to agriculture only if agricultural fields or orchards are present in the surroundings. A flood protection service exists only if beneficiaries (real estate or other economic goods) are located in the flood plains. A recreational service comes into existence if an area is spatially accessible to people and is actually used for recreation. Burkhard et al. (in press) mention that supply of ES means the "actually used set of natural resources and services" and not the "potential supply". However, we believe that a LCC-based approach does not (spatially) consider whether people are benefiting from ES which are produced in a certain LCC. Burkhard et al. (in press) in fact refer to potential supply and not to actually used ES, which would contradict their definition.

\section{Scoring system for supply and demand}

We believe that there are critical disadvantages of applying a qualitative scoring technique to rank supply and demand (as in Burkhard et al., in press, Figs. 2 and 3). Without a more detailed description of the methods used to score supply and demand, the scores themselves can be disputed. For example, the scores they assign for the service "global climate regulation" give the impression that LCC "broad-leaved forest" is in principle able to supply global climate regulation (score 4) at comparable levels to demand on LCC "road and rail networks" (also scored with 4), which is far from realistic (J anssens et al., 2005). In order to adequately compare supply and demand of ES more quantitative methods of scoring are needed.

\section{Further advancing the methodology for mapping supply and demand}

Many ES can only be finally consumed after economic agents (e.g. ecosystem managers, primary resource exploiters, private persons) have exploited services, which usually involves applying a combination of natural, social and manufactured capital (Boyd and Banzhaf, 2007; Bateman et al., 2011). This has consequences for two important issues related to mapping supply and demand of ES: first, the use of appropriate indicators, second, the point in time and space at which an ES is demanded. In many cases, people 
do not have a demand for the actual ES but for final processed goods that are the result of a production chain. Although, for example, a common indicator for the ES "timber" is $\mathrm{m}^{3}$ round wood per hectare and year, this is not what people finally consume (i.e. which enters their utility function). Instead of buying round wood they purchase wood in the form of firewood, a plank, or a kitchen table. As a result, the indicator for ES demand of the final beneficiary (e.g. a kitchen table) would not match anymore with the indicator for supply (e.g. $\mathrm{m}^{3}$ round wood), making a comparison difficult. Where to locate demand in the case of these processed goods? The options are manifold: at the place of harvest, at the sawmill, at the carpenter or at the household. If we decide for the final point of consumption we run into an inherent data and complexity problem: it will not be clear where exactly the wood originally comes from. Therefore, we argue that the point of the last contribution of an ecosystem to the existence of an ES would be most consistent for locating demand for ES that are transportable and highly processed after extraction and before consumption. In short, the demand for the ES "timber" should be mapped at the point where the trees are felled. In the case of wood provisioning, this is also where supply of ES takes place. This demand can then be higher (overexploitation) or lower than what ecosystems can potentially supply in a sustainable manner. We propose to map supply of an ES at the location where the service is generated by the ecosystem. Hence, in our proposal, supply is mapped according to the capacity to provide a service (which has also been referred to as ecosystem function). In the case of timber, supply is mapped according to the capacity of an ecosystem to provide timber, irrespective of the actual harvest of timber. We tentatively suggest the following decision rule to define the location of demand for ES. If an ES is spatially confined, demand should be mapped at the location where the final beneficiary uses the ES. We consider a service as spatially confined if beneficiaries of the final service can be delimited. Beneficiaries can be delimited if they can be coupled to ES production within the boundaries of the study area. Furthermore, they can be delimited if the specific ES cannot easily be substituted by ES from other ecosystems in the current space and time. This means that the service is not tradable or actively transportable outside the ecosystem. Example ES are flood protection, air quality regulation or recreation. If an ES is not spatially confined, (i.e. if beneficiaries of the final service cannot be delimited within the boundaries of the study area) demand for this service should be mapped at the place of the last contribution of the ecosystem. This means that an active transport is possible after the last contribution of the ecosystem to the existence of the service. Example ES are crops, capture fisheries or timber.

\section{Conclusion}

We believe that a balance of supply and demand of ES can provide meaningful insights to policy makers only if the respective ES shows a degree of rivalry (rival or congestible) and if supply and demand can be measured in similar and comparable units. We suggest to map demand either at the place where the final beneficiary uses the ES (spatially confined services) or at the ecosystem (spatially non-confined services). Demand of ES would then occur where ES enter either a utility function (of a private household) or a production function (of, e.g. an ES agent). Demand is therefore the actual use of ES. We could then map supply of ES as the potential to deliver what we call the last contribution of the ecosystem. An example is annual regrowth of a population of trees to harvest in a sustainably managed ecosystem. This supply can be higher or lower than actual demand, which gives parsimonious but policy-relevant information on (non-) 
sustainability. With our ideas we enhance terminological and conceptual clarity of ES mapping and enabling the delivery of profound information to policy makers.

Matthias Schröter*, Roy P. Remme, Lars Hein

19 December 2011

\section{Acknowledgement}

We gratefully acknowledge financial support by the European Research Council under grant 263027 (the ‘Ecospace' project).

\section{References}

Bateman, I.J., Mace, G.M., Fezzi, C., Atkinson, G., Turner, K., 2011. Economic analysis for ecosystem service assessments. Environmental and Resource Economics 48, 177218.

Boyd, J., Banzhaf, S., 2007. What are ecosystem services? The need for standardized environmental accounting units. Ecological Economics 63, 616-626.

Burkhard, B., Kroll, F., Nedkov, S., Müller, F. Mapping ecosystem service supply, demand and budgets. Ecological Indicators, in press, http://dx. doi.org/10.1016/j.ecolind.2011.06.019 .

Fisher, B., Turner, R.K., Morling, P., 2009. Defining and classifying ecosystem services for decision making. Ecological Economics 68, 643-653.

Janssens, I.A., Freibauer, A., Schlamadinger, B., Ceulemans, R., Ciais, P., Dolman, A.J., Heimann, M., Nabuurs, G.-J., Smith, P., Valentini, R., Schulze, E.-D., 2005. The carbon budget of terrestrial ecosystems at country-scale-a European case study. Biogeosciences 2, 15-26.

Kemkes, R.J., Farley, J., Koliba, C.J., 2010. Determining when payments are an effective policy approach to ecosystem service provision. Ecological Economics 69, 2069-2074.

Willemen, L., Verburg, P.H., Hein, L., van Mensvoort, M.E.F., 2010. Spatial characterization of landscape functions. Landscape and Urban Planning 88, 34-43. 